\title{
SUSTAINABILITY IN ENERGY PRODUCTION
}

\author{
G. GENON, D. PANEPINTO \& F. VIGGIANO \\ DIATI Department, Politecnico di Torino, Italy
}

\begin{abstract}
The requirement of energy in different human activities is continuously increasing; from the energetic production, chiefly by thermal systems, important and worrying environmental problems are generated: there are concerns about climate change, local air quality worsening, exhaustion of resources and land use change. To limit these negative aspects, policies of reduction in energy use must be first proposed; besides different technological, economic and planning solutions can be considered; their effect must be carefully assessed, as concerns effectiveness and practical implementation. The final political decision must consider the different tools that are at disposal, in order to define the best approach for the satisfaction of necessities with the minimum consequent impact.
\end{abstract}

Keywords: climate change, energy production, environmental compatibility

\section{INTRODUCTION}

The requirement of energy for our activities presents different values in countries of different development and social structure, but it is in any case very important; in this connection, industrial activities, heating and refrigeration, and transport must be considered.

With some differences between more or less developed areas, but with a quite general trend, it is very easy to observe a strong positive correlation between parameters that are indicators of satisfaction of needs or economic development (internal product, total income, industrial production and revenues of the families), and consequent energy production and use [1,2] (Fig. 1).

But, from the other side, and in opposition with the positive aspect of satisfaction of human needs, this productive need leads to important negative aspects as concerns the quality of the environment, in account of over-exploitation of natural resources and immission of residual pollutants in different media.

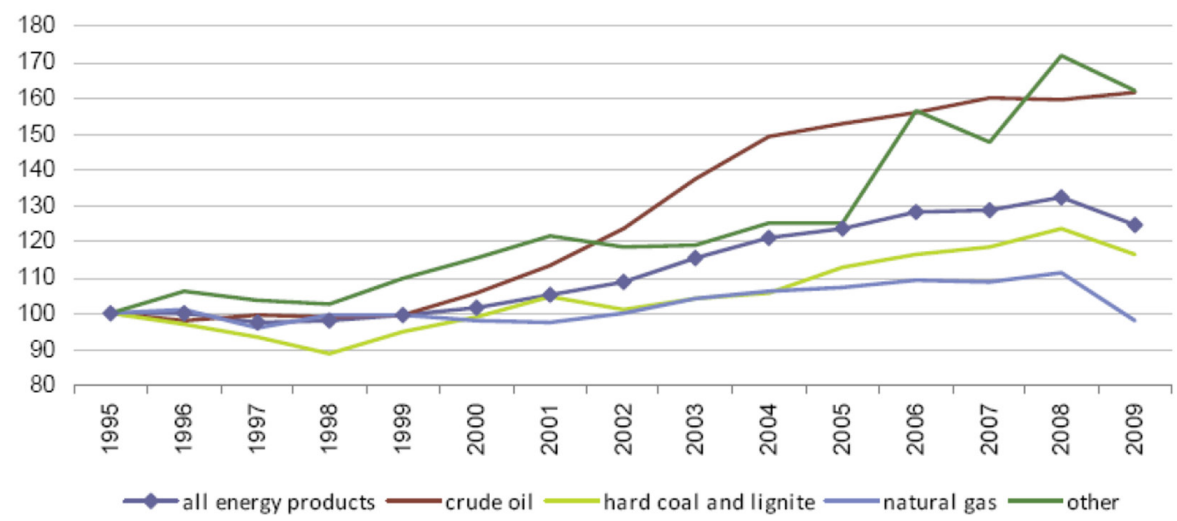

Figure 1: Trend in energy production. 
It is very worrying to consider in this sense a gradual trend of climate change, a modification in land use and biodiversity, an impact in air, water and soil quality, a potential exhaustion of natural resources (fossil fuels and land for energy crops are good examples) [3].

In consideration of the presence and weight of these impacts from energy production, many supra-national authorities and governs, on the basis of indications of regulating agencies, tried to individuate operative tools and perspective strategies useful to limit this negative consequence.

To this aim, they defined and acquired interventions and strategies based on operative practices, right choice of energy sources, best utilization of the produced energy, territorial planning strategies, technological containment tools and scenarios definition.

To establish a rational way of intervention and to define an ordered and useful assessment of different intervention instruments, the following aspects must be considered:

- Individuation as a principle and definition in the practical implementation of an operative instrument.

- Evaluation of the effects of the proposed instrument for the impact limitation.

- Estimation of the effects of the proposed tool on the modification of the quality of the receiving environment.

- Aspects of feasibility and practical implementation, cost of adoption and consequences on the cost of the produced energy.

- Consideration of the effect for limitation of impact and improvement of energy production sustainability, and evaluation of benefits in terms of reduced externalities.

- Final decision about the implementation of the evaluated solution, in account of feasibility, costs, benefits and reliability.

In the present paper, the over-indicated different steps in the definition of an acceptance strategy will be briefly discussed; some practical examples of implementation and the consequent obtained results will also be discussed.

The examples are chiefly directed to European countries, where the intensity of energy requirement is very high, and the concerns for environment quality are strongly present: consequently, many technologies and strategies for sustainability establishment have been realized and put into operation.

In consideration of the general worldwide trend of the considered phenomena, the introduced examples more in general can be considered as an indication in a more enlarged perspective for developing countries.

\section{STRATEGIES FOR LIMITATION OF ENERGY PRODUCTION}

A first starting point possibility that must be considered for any policy directed to right containment of impact is the evaluation of the possibilities, costs and benefits of a limitation in the production of energy.

It must be taken into consideration the meaning of energy production as a tool useful to satisfy industrial requirements or to guarantee to the population desired levels of quality of life, as concerns mobility, heating, air-conditioning; on this basis, a containment requires the application of a de-coupling between economic development and energy production.

To obtain this result, many positive examples have been introduced in practice in many territorial situations; we will consider thermal energy consumption, electric needs for industrial operations and fuel requirement for transport: 
- As concerns the thermal energy used for heating of houses and buildings, in many countries specific laws have been introduced in order to limit the consumption of energy and to increase the energetic efficiency of the structure of the constructed system [4]: right choice of construction materials, careful realization of insulating systems and time scheduling of use of thermal energy are important instruments in this sense; the specific energy requirement of the actual houses has been reduced; also the aspect of the renovation of the ancient buildings, and the adoption of innovative technological solutions and suitable materials in new buildings are very important instruments.

- The industrial system, chiefly for reason of costs, but now also in consideration of incentives and regulations about energetic efficiency [5], has traditionally evaluated all the possibilities to reduce the specific energy consumption for unit of product; very important examples, by taking into account the high specific energy requirement of these sectors, are the cement and lime industry, the iron and steel industry and the petro-chemical industry; the utilization of more efficient and performing plants, the definition and adoption of process modifications directed to containment of losses, a verification of raw materials, additives and chemicals (in account of their thermodynamic and thermo-technical characteristics) are important instruments that have been used to obtain this improvement (Fig. 2).

- With reference to the fuel consumption for private or public transport [6], in a similar manner it is possible to observe a progressive trend to the realization of more efficient engines; the tools were adoption of innovative processes, right choice of materials, reduction of weights, implementation of operative tools for vehicles conduction and control; also in this case, it is important to observe that a continuous increase in the requirement for the human mobility should avoid a directly connected consequence in terms of energy requirement, pollution emission and environment worsening (Fig. 3).

GDP and energy

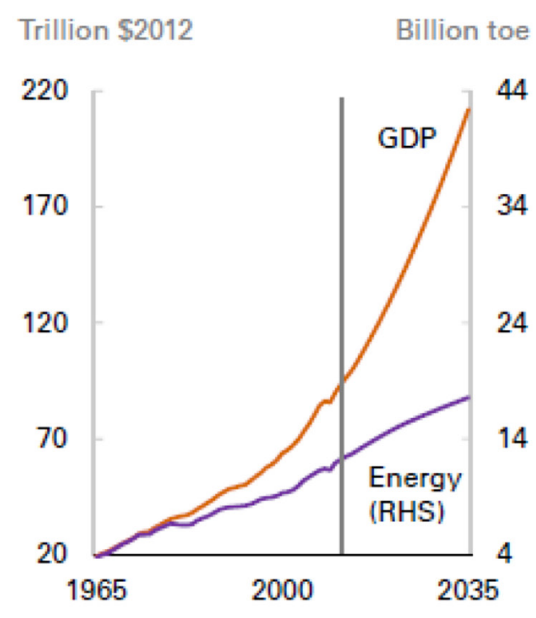

Shares of primary energy

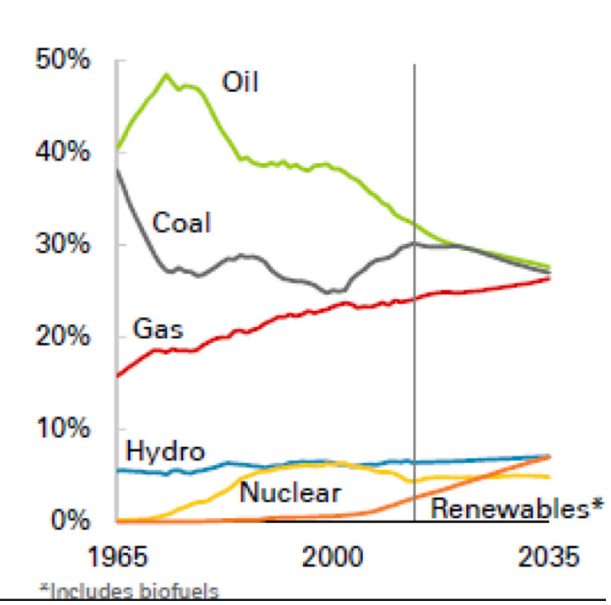

Figure 2: Decoupling of industrial use. 


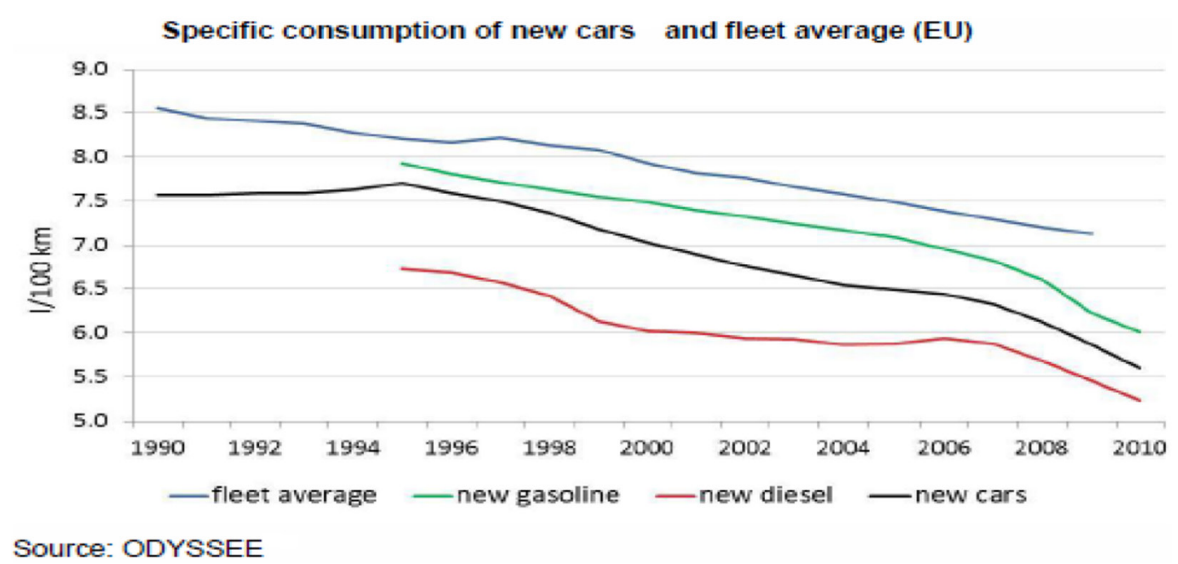

Figure 3: Energy efficiency in the transport sector.

It is important to consider the fact that the target of reduction in the use of energy from many years has been very carefully implemented from the operators, in account of reduction in operative costs.

The development of systems of energy reduction and process improvement has been conducted until to a breakthrough economic limit point, and not more; from there, the achievement of an energy consumption decrease is more expensive in comparison with the reduction in operating costs.

From the technological and process points of view, it is possible that, as concern operativity and choice of process conditions, conditions for a further energy reduction and a more pronounced de-coupling could be proposed but, from a simple industrial point of view, these improvements are today not convenient for the proponents.

To overcome this obstacle to development of innovating systems, it is necessary that the policy-makers introduce systems of incentives and awards directed to improve correct policies, and to help the operators to adopt systems that lead to more efficient and less consuming production systems. This will be one of the tasks that are required from the public authorities, as it will be discussed in a following point.

\section{BEST USE OF THE PRODUCED ENERGY}

It is today and in the future a fundamental option for the choice of the thermal production of energy, and the conversion of the produced energy in electricity.

This operation is characterized from very high levels of efficiency, with performances that are continuously increasing, chiefly for large plants [7].

In this perspective, it is at the same time very important to consider the option of the co-generation, leading also to the utilization of the residual produced heat; the thermal energy fundamentally can be used for district heating, but it is also possible to evaluate solutions of district cooling, or, with some limits as concerns localization and dimensional compatibility, direct industrial use (Fig. 4).

The extraction and transfer of thermal energy normally leads to a reduction in the electric power that can be transferred to the grid; from the other side, it is possible to obtain the elimination, or at least the reduction, of dispersion of residual low-temperature heat that arises from direct immission in water bodies or from adoption of impacting cooling towers. 


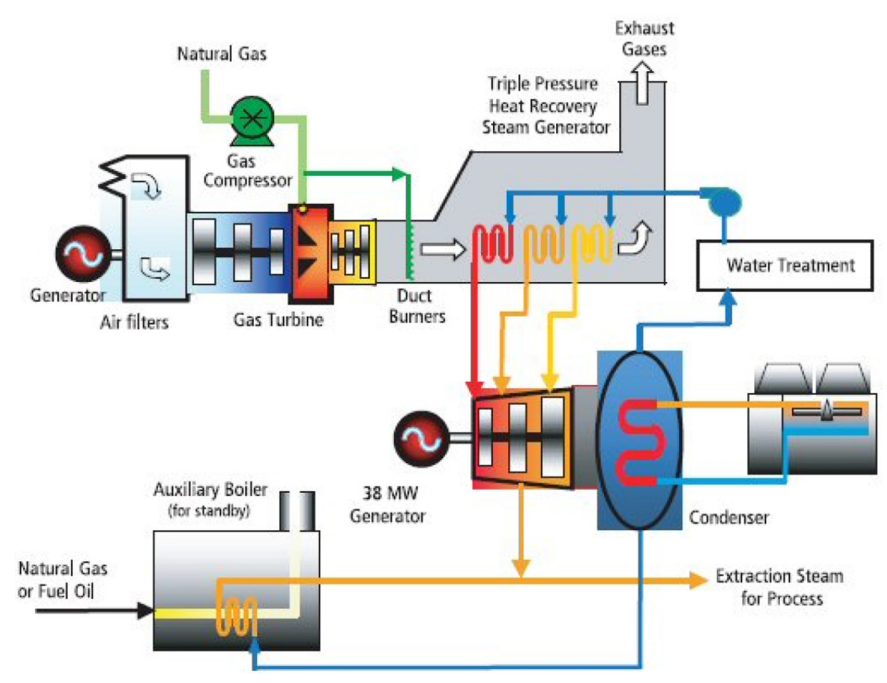

Figure 4: Co-generation.

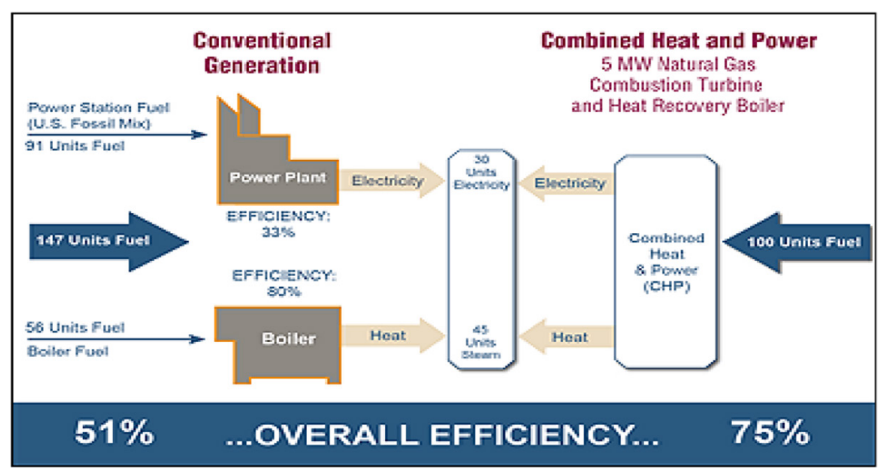

Figure 5: Conventional generation and co-generation: overall efficiency.

The perspective of co-generation leads to easily defined advantages from the point of view of limitation in GHG (greenhouse gas) emission, as the residual heat that is utilized can substitute other local energy sources, and consequently avoid their specific emissions (Fig. 5).

Besides to this advantage from the point of view of total efficiency and limitation of effect on climate change, another advantage can also be observed for the local air quality; in fact, an important aspect of environmental compensations is obtained; as there is the substitution of many local sources of pollutant emissions (normally un-controlled and localized in proximity of residential zones) with a transfer of heat coming from a controlled, delocalized source [8].

On the basis of these aspects, both from a thermodynamic efficiency point of view, and also by considering the positivity in terms of GHG limitation and substitution of local emissions, a policy of adoption of systems of co-generation must be very strongly suggested.

From the point of view of advantages that can be estimated, a verification of the positive aspects of this configuration can be obtained by means of an environmental balance; it 
consists in an estimation of the total added and substituted emissions, and in an assessment of the effects of the modified emission scenario on the local air quality; this predicting procedure will be better described in a following paragraph.

A limit in the implementation of co-generation systems arises from the fact that, while the electric energy can be very easily transferred to a collection and distribution grid, and it can be conveyed to long distances, the thermal power requires an expensive network of distribution; moreover, the efficiency of utilization sharply decreases with the distance from the source.

Therefore, there is an important aspect of territorial planning that must be considered, and chiefly the distribution of activities is very meaningful to this purpose; in fact, it is very important to verify, in areas as close as possible to co-generation systems, corresponding users of thermal power, with enough energy absorption capacity.

Also, the aspect of continuity of co-generation opposite to the season dependence of thermal use for district heating is an aspect of important concern; to this aim, the possibilities for district cooling and the presence of continuous industrial thermal energy users are very positive aspects.

A last aspect that must be considered in this perspective is the strict operating and implementation cost aspect; in fact, in many cases, the revenues from the pure electric production are higher in comparison with those that could be obtained in the hypothesis of co-generation.

It is necessary in fact to consider that different prices and remuneration can be obtained for different forms of energy, and also to take into account the expensive needs for thermal power transmission (network creation and distribution).

Also in this case a negative economic operational aspect of co-generation is in opposition with a positive aspect of co-generation as concerns the environmental point of view. Therefore, an economic policy adopted from the public authorities directed to support the co-generation as a more environmentally acceptable solution could be an important help.

\section{CHOICES FOR GHG LIMITATION}

An absolutely important problem connected with the production of energy in case of thermoelectric plants, as in general in many thermal apparatus, is the generation of GHG and their contribution to climate change (Fig. 6).

About it, it is fundamental to consider that the climate change is today probably the most important environmental problem that is in front of our society, with an enormous dimension of the problem, and a general concern without differences in the different geographic areas.

Moreover, in account of the policies that must be implemented, it is very important to consider that in this case there is a fundamental difference in comparison with all the other pollution problems: in fact, for GHG very probably, it is impossible to consider only technological solutions, also if from them some help could arise; for a meaningful improvement of the situation, a completely different multi-oriented approach is required [9].

To move in direction of limitation of GHG generation, the first obvious approach is an increase in non-thermal energy production systems (hydroelectric, solar, wind and potentially nuclear); the trend in favor of these forms of energy has been implemented and it will be certainly increased in the next years (with exception of nuclear energy, where there are different problems) [10].

Despite this aid from natural energy sources, for a long period and for many territorial situations, it seems very difficult to avoid an important utilization of thermal systems to produce energy.

In this situation, the choice of the most acceptable fuel is the first aspect to be considered: a first very elemental consideration, from the stoichiometric and energetic point of view, is 


\section{End-use greenhouse gas emissions from energy use in EU-27 in 2009}

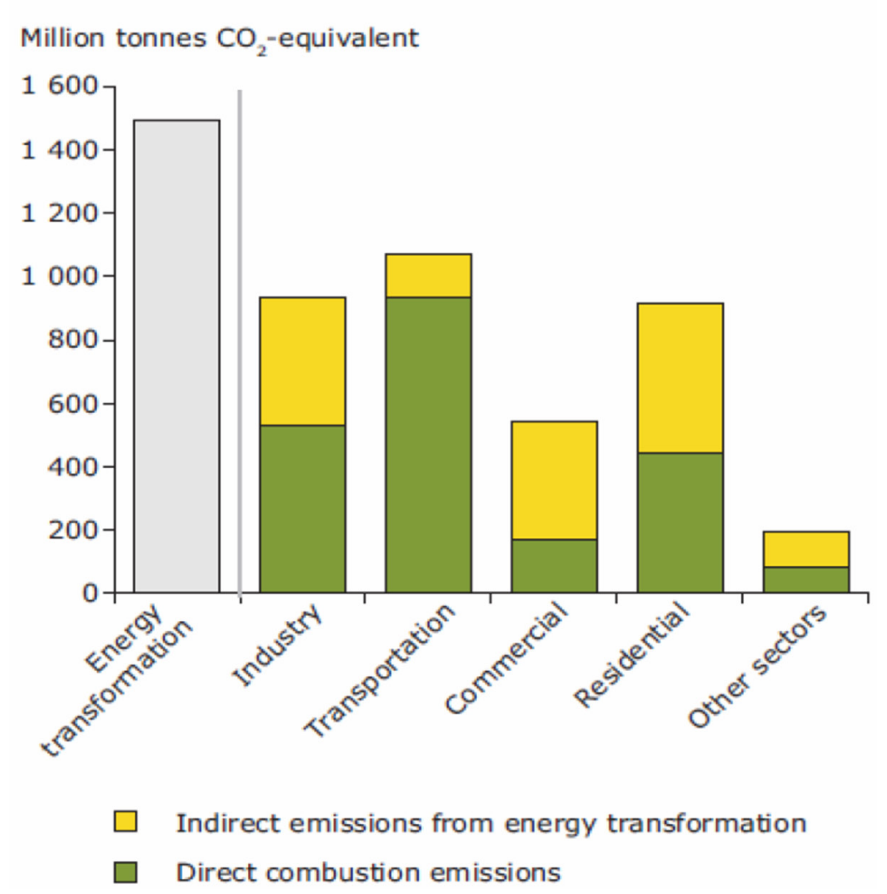

Figure 6: Greenhouse gas (GHG).

that between fossil fuels, there is a ranking in account of the carbon content and calorific value.

In this manner, methane is better than coal; moreover, with consideration of carbon credit corresponding to atmospheric sequestration, renewable biomass is better than methane.

To establish a first range of specific carbon dioxide emission, it is necessary to consider both mass and energy balances of the process of combustion and energy production, and together with them it is required to take into account the carbon debt that is connected with the production of the fuel; so it is possible to evaluate the specific $\mathrm{CO}_{2}$ production for each type of considered fuel, and consequently its meaning from the point of view of climate change [11].

In a more general perspective, it is important to underline the advantage of use of biomass in account of its renewability and consequent capacity to balance carbon sources with carbon sinks.

But from the other side, the environmental local and global loads (energy consumed in growth, water use, land use change and modification in biodiversity) that are connected with the choices of different types of biomass must be considered; also the ethic aspects connected with the use of food or non-food carbonaceous material must be carefully evaluated.

As it was previously established, the co-generation is another very important tool that reduces the emission of $\mathrm{CO}_{2}$, in account of the efficiency that can be obtained. Energy and mass balances also in this case can be considered a meaningful instrument to evaluate the positivity of a chosen strategy. 


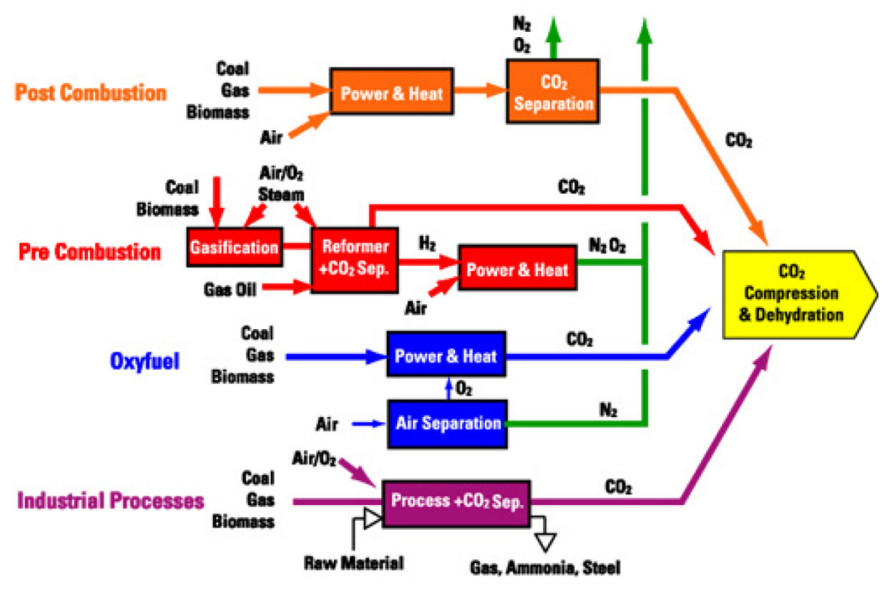

Figure 7: Scheme of CCS.

As it was seen, the main roads to reduction of GHG emissions consist in the use of non-thermal energy, and right adoption of biomass as fuel; but it is also useful to discuss about the possibility to adopt end-of-pipe solutions, and particularly systems based on CCS (Carbon Capture and Storage) [12] (Fig. 7).

These systems that have been largely studied, tested at different levels of scale, and implemented in some demonstration plants, lead to the final sequestration of the produced $\mathrm{CO}_{2}$, and consequently to a technological solution to the carbon dioxide problem.

Their result from the point of view of industrial engineering is absolutely positive for the $\mathrm{CO}_{2}$ removal, and probably also for the performances as concerns the final destination for the final segregation of the sequestered carbon.

But the fixed cost for the implementation of the operation must be considered, and also, as concerns the operative aspect, the loss of efficiency that the implemented solution requires; also the energy contribution that arises from the operations of $\mathrm{CO}_{2}$ absorption, transport and final segregation must be taken into account [13].

By considering all these aspects, it is very difficult to forecast significant developments for this strategy; moreover, it must be taken into account the higher economic advantage that for the producers corresponds to entering in the market of carbon credits instead to realize and operate systems of CCS.

On these bases in the actual and near future situation, it is very difficult to individuate an inversion of the negative aspect, and consequently to forecast a possibility of a significant development of this strategy.

In conclusion, the technology probably is not able to furnish solutions to the ever increasing production of GHG, on the basis of the impossibility to avoid the use of thermal systems for energy production.

Only with a very radical decision at the level of governs, it is possible to forecast a trend of lower increase, by strongly suggesting and implementing forms of less invasive, more renewable energy, or by sustaining strategies of CCS with very important financing aids.

The right choices in terms of type of fuels and a strong attention on the aspect of thermal efficiency in the utilization of fuels can bring some partial supports to the approach to a real limitation of GHG introduction in the atmosphere [14]. 


\section{TECHNOLOGICAL SOLUTIONS FOR AIR LOCAL IMPACT LIMITATION}

The most important form of local impact from thermal energy production consists in the emission of combustion pollutants, and in the consequent modification of air quality (Fig. 8).

For this aspect, first the emission of nitrogen oxides must be considered, with the consequent acidification effects and the formation of secondary aerosols (fine dusts); afterwards with solid fuels, the emission of acidifying sulfur oxide must be taken into account; with solid fuels also the emission of particles and fly ashes must be considered; potentially in these materials traces of volatile heavy metals and micro-pollutants can be present. Lastly, carbon monoxide and residual un-combusted organic substances and products of partial oxidation can be present in the emissive flux.

To limit this impact, many advanced treatment systems have been studied, adopted and are consolidated in the operative practice; they are very well described in the BREF (Best REFerence) for the specific sector; in this document, there is a complete description of properties and performances of BAT (Best Available Techniques) of this technological sector [15].

On the basis of the technological choices normally with more performing systems, there is a decreased concentration of pollutants in the emission flux; this fact leads to a progressively higher investment, and higher operative cost, and frequently also higher difficulties for the disposal of residual wastes.

On the other side, it must be considered that a decrease in the pollutant concentration leads to an increase in air quality in the surrounding of the plant, and consequently to a reduction in the external costs, for population, ecosystem and buildings.

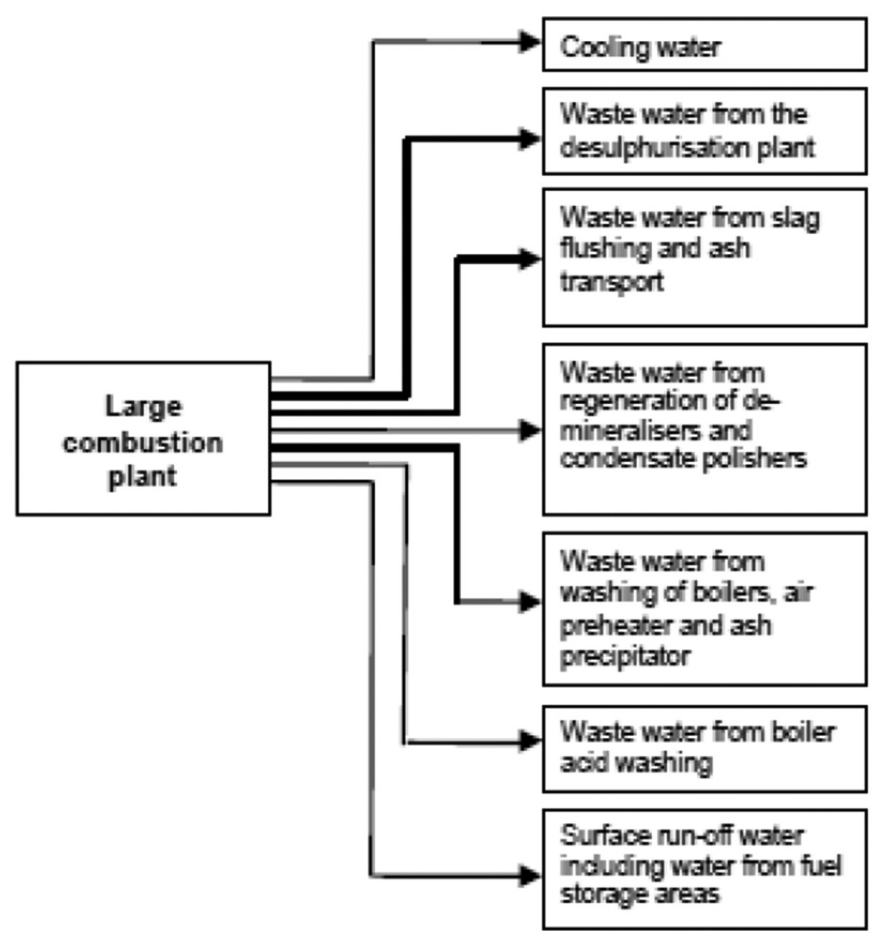

Figure 8: Effluents from fossil fuels fired. 
The counteracting aspects of industrial cost increase and external cost decrease, with their well-defined numerical values, can be used to establish an optimal trade-off between the two voices of cost. Also, if normally it is required a comprehensive political approach to compare these costs, from this trade-off an optimal level of pollution removal can be defined in a rational way.

In case of emission from large plants that are used to produce energy, this technological approach and the consequent required evaluation about the limit to be obtained is the main road to containment of pollution; from this approach it can be obtained the more sustainable situation.

On the contrary, in many case, it is required to consider the atmospheric emissions from small distributed sources (the most important example of this type of impact is corresponding to emissions from cars for private transport, but also combustion for heating of residential buildings must be considered).

A technological system for the removal of the emitted pollutants can be obtained, and it has been well defined from many specific studies; very often on the other side its implementation is associated with very high costs, in account of the large number of small-scale sources of emission.

Moreover, for some very important situations, like in the case of nitrogen oxides, the implementation of highly performing systems for efficient removal of pollutants is not yet at disposition on the scale of small flow-rate emissions.

In this situation, the technological system as the main road to avoid pollution cannot be proposed, and on the contrary it seems more convenient to consider complementary approaches.

In order to obtain an efficient approach is necessary the adoption of right choices as concerns fuel sources, or effectiveness of engines or thermal systems, that are solutions leading to reduced consumptions. Moreover planning and scenario solutions seems to be very convenient, and this aspect will be dealt with in the next chapter [21].

\section{DEFINITION OF PLANNING CRITERIA FOR IMPACT LIMITATION}

To limit the environmental impact of energy production, it is very important to consider the aspect of localization, with reference both to large plants, as thermoelectric generation plants, and also to distributed small plants, such as vehicles, domestic boilers or micro-co-generators.

In fact, the environmental impact aspects that are derived from different phases of energy production are strictly linked to the area of operation: many aspects must be considered in this sense, such as the access to raw materials, the loads arising from transport, the effect of emission on the quality of receiving media and the possibility to use in its integrality (heat and power) the produced energy.

All these aspects are strictly bound to the position where a plant or an apparatus is operating, and so it is very important to consider where the structure is located.

To correctly evaluate all these aspects, the information that must be required about the receiving area are as follows $[17,18]$ :

- Presence or possibility to obtain biomass useful for energy production.

- Possibility to use resources, marginal soils and secondary fertilizers for the growth of sustainable resources destinated to fuel production.

- Connection to transport systems for solid fuels.

- Possibility to transfer residual heat to existing or proposed district heating networks, or to large industrial users.

- Conditions of local air stability, dispersion conditions and stagnation possibilities. 
- Possibility to use residual ashes from solid fuels combustion for operations of soil remediation.

- Presence of common transport systems for needs of mobility of the population.

The information so required can be obtained by a careful analysis of the area where the energy production must be realized; this analysis is directed to the evaluation of natural aspects and perspectives of resilience, verification of infra-structural situation, consideration of the present industrial activities, and consideration of social and operative projects for the development of the considered area.

From a co-ordinated lecture of all these aspects, the public authority can obtain elements for a planning activity, directed also to verification of aspects of environmental compatibility [19].

\section{ECONOMIC INSTRUMENTS}

Besides technological systems and planning decisions, also economic and financial instruments can be considered to obtain a reduction in the environmental impact of energy production, chiefly as concerns the generation of GHG [20].

The principal instruments that can be considered in this direction are [21]:

- Carbon tax.

- Cap and trade.

- Green certificates.

As concerns carbon tax, this is a simple instrument that determines a tax on the emission of carbon dioxide that must be paid from the producer: it is useful from one side for financing environmental activities. From the other side, it represents a strong dissuasion tool directed to producers to obtain from them a reduction in the level of emission (Fig. 9).

A positive aspect is the fact that it is a fair instrument, as it is addressed with the same intensity to all the contributors to emissions, and chiefly, from the environmental point of view, it has certainly an immediate and visible practical effect on emissions. From the other side, the limits of this instrument correspond to the fact that it is impossible to establish if the effect of the instrument leads to the establishment of desired values for the atmospheric level of carbon dioxide deriving from emissions, and which is the real effect on the climate change [22].

On the contrary, the cap and trade instrument fix for the total emission of carbon dioxide of an established area a desired objective, general for the totality of the emitters; this permissible total flux should be correctly determined in account of its consequences in terms of allowed modification of air quality.

Afterwards, the distribution of reduction between the producers is left to an agreement between them, with the over-indicated limit of total emission.

This instrument has the very important advantage to be a result directed tool, and from this point of view it is a meaningful control tool, but from the other side it can be very unfair between the different operators, as the application depends on respective implementation costs; and also the practical application of the verification of the exchange of emission credits, under the general established limit, is quite difficult [23].

A third instrument that can be introduced is a system of awards, in terms of increase of price paid to the producers, that can be established for the forms of energy that are considered 


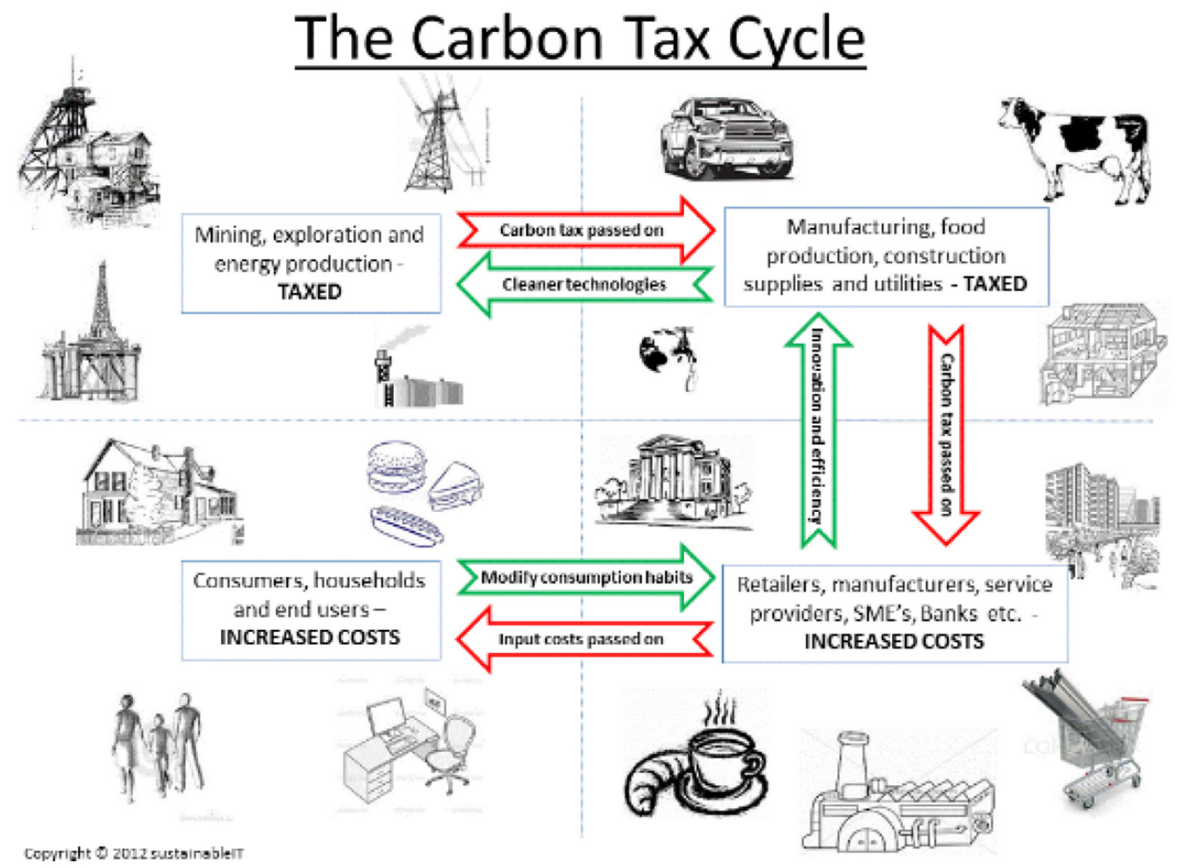

Figure 9: Implementation of carbon tax.

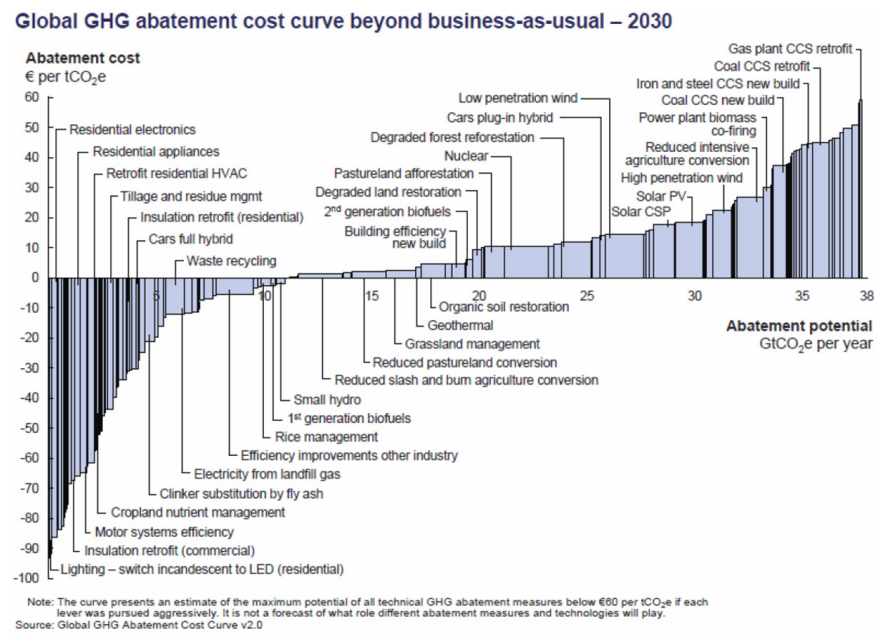

Figure 10: GHG abatement.

more useful in order to limit climate change; the price at the moment of transfer of the energy to the grid is increased by a quota that is fixed in order to encourage the more acceptable forms of energy production, like renewable energy or non-thermal energy.

Also, this economic tool can be considered as a fair solution directed to all the operators; but only with a final budget and analysis of results, it is possible to establish which is the real effect of this policy in the attainment of the objectives [24,25] (Fig. 10). 


\section{ENVIRONMENTAL BALANCE AND ASSESSMENT OF LOCAL EFFECTS}

To evaluate the local consequences of energy production, it is fundamental to consider the instrument of environmental balance: it consists in the comparison between the introduced pollutant loads deriving from the assumed scenario of energy production, and the pollutant loads that can be considered as eliminated, in account of the substitution of existing energy sources.

This instrument, in its more simple application, considers only the stack emissions, and is based on energy and mass balances for the compared systems (the new one and the existing scenario), by considering the plant impact factors of these systems (fluxes of emitted pollutants).

The environmental balance in this form is of simple evaluation and of a structure that can be very easily reconstructed and checked; it leads to a result that can be immediately appreciated [26].

From the other side, it is probably less correct and of lower general value in comparison with an evaluation conducted with the tool of Life Cycle Assessment: in fact, it considers the stack emissions only, and it does not take into account the complete process structure that comprises also fuel production, pre-treatment and other preliminary operations.

An evaluation that is conducted with the approach of LCA (Life Cycle Assessment) is absolutely more difficult to be performed, it requires the introduction of many process and environmental parameters that are difficult to estimate; the reconstruction of the numerical results, in many cases arising from utilization of quite general data banks, is in many cases impossible.

The advantage of the environmental balance is that the easy lecture of the results can be very important for a first evaluation of a proposed scenario.

In a simpler form, an environmental balance, in a definitely more complicated form, an analysis based on LCA leads to an estimation of emissive fluxes of pollutants, coming from the evaluated technological structure or the general scheme of energy production (Fig. 11).

This estimation is substantial information in the assessment of compatibility for a proposed solution, but it does not correspond immediately to an evaluation of the consequence of the activation of an energetic system on the quality of the receiving environment (air quality chiefly, but also quality of soil, or characteristics of surface or underground waters interested to emissions).

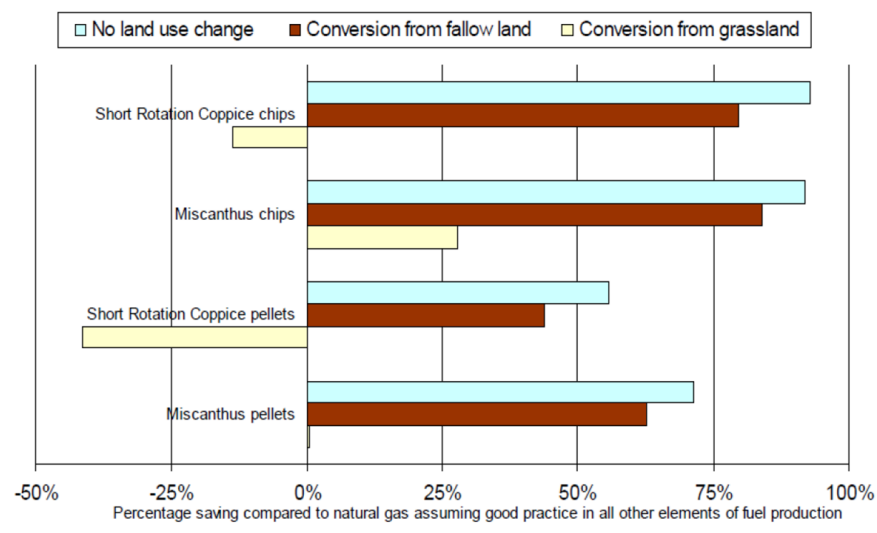

Figure 11: The impact of direct land use change on emission reductions. 


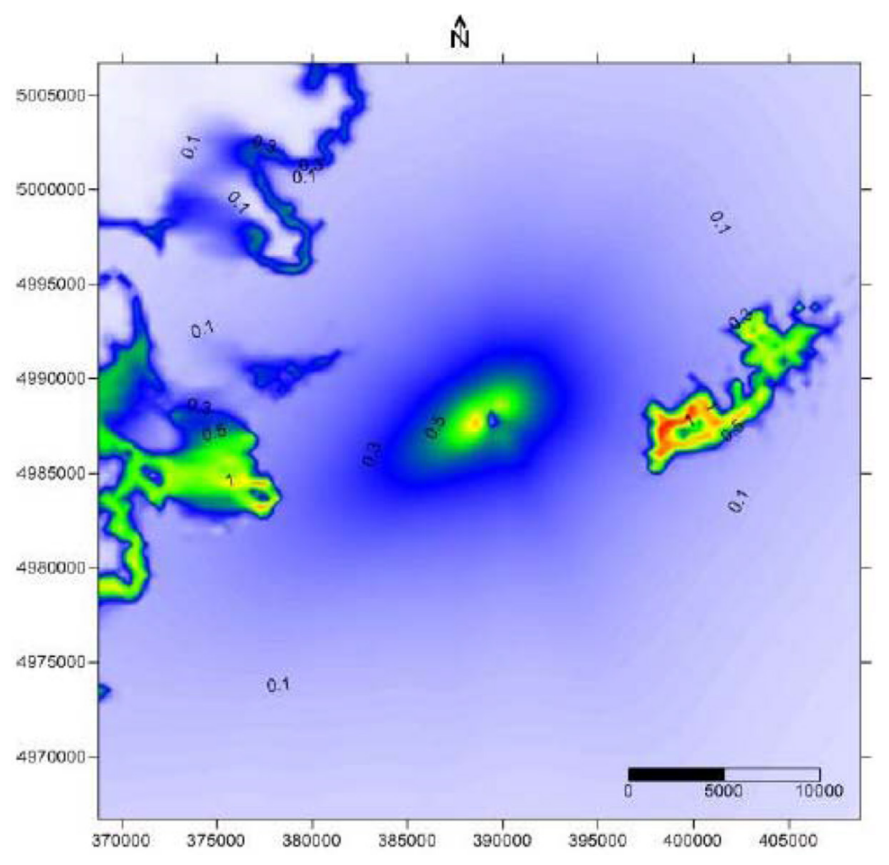

Figure 12: Assessment of local impact.

The evaluation of this modification of quality must be considered as the true indicator for the compatibility, and at the end it determines the acceptability of a proposed energy solution depending on its results.

To evaluate the meaningful aspect of transfer of pollutants on receiving media, the estimation is in any case more difficult than with a simple environmental balance [27].

First of all, it is necessarily specific for the considered site, and so it must consider specific well-determined and not literature values; but chiefly it is important that it must be able to describe all the mechanisms and the phenomena that transfer the pollutant from the source to the surroundings targets.

To implement this knowledge, it is required to be able to use a predictive model that describes the physical, physico-chemical and chemical phenomena that are involved in the transfer of pollutants; all the specific parameters that are involved in the transfer and transformation phenomena must be known (Fig. 12).

Against the complication of the calculation, it must be observed that the final result is absolutely more meaningful in comparison with simple environmental balance; in some cases, it can lead to estimations that are different from first instance environmental balance results $[28,29]$.

The indication of acceptability, in terms of evaluation of the modification that is introduced in the quality of the receiving environment, depends on the natural characteristics of the receiving media, on the distribution of targets, on the transformation phenomena and on the transfer paths of the introduced pollutants.

In some cases, also in the presence of a negative environmental balance (that is represented by an increased load coming from a proposed technological scenario), in the final evaluation an improvement in receiving media quality can arise; some examples of this condition are well present in the specific literature. 


\section{POLICY DECISIONS AND CONCLUSIONS}

In the previous chapters, some general considerations have been introduced as concerns the consequences of different choices concerning energy production on the quality of general environment.

The problem is obviously of the highest moment in consideration of the ever increasing demand for different forms of energy, and the global consequences that are originated, and are able to substantially modify our natural environment.

At the end of all the evaluations concerning the scenarios and the consequences of different choices as concerns the energy production, the final decision concerning the most acceptable solution must be assumed from the public authorities.

The considered aspects correspond to many sectors:

- Availability of different quantities of fuels or original raw materials, their cost, distance of origin, cost and externalities for transport.

- Meaning of utilization of renewable energy sources for the limitation of GHG production.

- Capacity of different forms of energy to satisfy the requirements of the society, and possibility to modulate different forms of energy.

- Effects of choices about energy systems on local media quality (air, soil and water) [30].

- Effect on employment and social aspects connected with the decisions about the chosen form of energy.

- Ethical aspects of different forms of energy production (food - non-food original biomass), alternatives with other possibilities to utilization of resources (food, raw materials, soil and water).

- Cost of energy production and cost for limitation of impact [31].

- Reliability of different forms of energy, future prospects and possibilities for emergency situations, and their consequences [32].

All the so indicated conditions must be considered in a comprehensive scheme from the public policy-makers, and a final choice must be realized.

This choice must be realized with a final global assessment of all the aspects; the technical elements that have been discussed in the previous chapters are not exhaustive for the final choice, but for a correct choice they cannot be disregarded.

Probably, there are no forms of energy that optimize all the different aspects, from a general political point of view; also from a strict environmental point of view, probably there are different counteracting consequences of the preferred schemes.

Examples are the choice in direction of the use of biomass, absolutely positive from the point of view of limitation in climate change, but that can be impacting and negative as concerns the local quality.

The different aspects must be in any case put into evidence, for a well-based decision.

The activity of researchers in the field of impact assessment and in general in the evaluation of consequences of process and plant solutions or effect on receiving media is very important: the final decision makers must have the right information for a choice where these important arguments must be put in the right light.

\section{REFERENCES}

[1] IEA Technology Roadmap, 2012, Bioenergy for heat and power, available at http:// www.iea.org/publications/freepublications/publication/bioenergy.pdf, 2012 (accessed 9 January 2014). 
[2] Aebiom European Biomass Association, 2013, European Bioenergy Outlook 2013 IEA World Energy Outlook;

[3] EU Energy Transport and GHG Emissions - Trends to 2050 - Reference Scenario, 2013, available <http://ec.europa.eu/energy/observatory/trends_2030/doc/trends_to_2050_ update_2013.pdf>, (accessed 9 January 2014).

[4] Climate Policy Initiative, 2011, Information tools for energy demand reduction in existing residential buildings, CPI Report, available <http://climatepolicyinitiative.org/ wp-content/uploads/2011/12/Information-Tools-for-Energy-Demand-Reduction.pdf>, accessed 01/09/2014;

[5] Park, C.W., Kwon K. S., Kim W. B., Min B. K., Park S. J., Sung I. H., Yoon Y. S., Lee K. S., Lee J. H., Seok J.2010, Energy consumption reduction technology in manufacturing - A selective review of policies, standards and research. International Journal of Precision Engineering and Manufacturing, 10, pp. 151-173. doi: http://dx.doi. org/10.1007/s12541-009-0107-z

[6] IEA. Technologies and Approaches to Reduce the Fuel Consumption of Medium and Heavy-Duty Vehicles, The National Academies Press, Washington, DC, 2010.

[7] Havelsky, V., Energetic efficiency of cogeneration systems for combined heat, cold and power production. International Journal of Refrigeration, 22, pp. 479-485, 1999. doi: http://dx.doi.org/10.1016/s0140-7007(99)00010-9

[8] Torchio, M., et al., Merging of energy and environmental analyses for district heating systems. Energy, 34, pp. 220-227, 2009. doi: http://dx.doi.org/10.1016/j.energy.2008.01.012

[9] SUNCOR, Report on Sustainability 2013, Greenhouse Gas Emissions: The Path Forward, SUNCOR Energy, Inc., available at http://sustainability.suncor.com/2013/en/environment/ghg-emissions-path-forward.aspx, 2013 (accessed 9 January 2014).

[10] IPCC, Guidelines for national greenhouse gas inventories. Energy; 2, available at http:// www.ipcc-nggip.iges.or.jp/public/2006gl/vol2.html, 2006 (accessed 9 January 2014).

[11] IEA Bioenergy, Using a life cycle assessment approach to estimate the net greenhouse gas emissions of bioenergy, available at http://www.ieabioenergy.com/wp-content/uploads/2013/10/Using-a-LCA-approach-to-estimate-the-net-GHG-emissions-of-bioenergy.pdf, 2011 (accessed 9 January 2014).

[12] IPCC, Special Report on Carbon Dioxide Capture and Storage,Cambridge University Press, available at http://www.ipcc.ch/pdf/special-reports/srccs/srccs_wholereport.pdf, 2005 (accessed 9 January 2014).

[13] Riekert, J.W. \& Koch, S.F., Projecting the external health costs of a coal-fired power plant. The case of Kusile. Journal of Energy in Southern Africa, 23, pp. 52-66, 2012.

[14] United Nations, A framework for decision makers. UN Energy, 2007.

[15] European Commission, Reference Document on BAT for large Combustion plants, 2006.

[16] Canova, A., et al., Emission characterization and evaluation of natural gas-fueled cogeneration microturbines and internal combustion engines. Energy Conversion and Management, 49, pp. 2900-2909, 2008. doi: http://dx.doi.org/10.1016/j.enconman.2008.03.005

[17] European Commission JRG, Indirect land use change from increased biofuels demand by Edwards, Mulligan, Marelli, 2010.

[18] Genon, G., et al., Energy and environmental assessment of small district heating systems: global and local effects in two case-studies. Energy Conversion and Management, 50, pp. 522-529, 2009. doi: http://dx.doi.org/10.1016/j.enconman.2008.11.010 
[19] Pohekar, S.D. \& Ramachandran, M., Application of multi-criteria decision making to sustainable energy planning - a review. Renewable and Sustainable Energy Reviews, 8 , pp. 365-381, 2004. doi: http://dx.doi.org/10.1016/j.rser.2003.12.007

[20] Stavins, R.N., Experience with market-based environmental policy instruments, Discussion Paper 01-58, Resources for the Future, Washington DC, 2001.

[21] National Renewable Energy Laboratory, Carbon taxes: a review of experience and policy design considerations, Technical Report NREL/TP-6A2-47312, 2009.

[22] Hwang, J.J., Policy review of greenhouse gas emission reduction in Taiwan. Renewable and Sustainable Energy Reviews, 15, pp. 1392-1402, 2011. doi: http://dx.doi. org/10.1016/j.rser.2010.08.010

[23] Moore, B. \& Wustenhagen, R., Innovative and sustainable energy technologies: the role of venture capital. Business Strategy and the Environment, 13, pp. 235-245, 2004. doi: http://dx.doi.org/10.1002/bse.413

[24] Enkvist, P., et al., A cost curve for greenhouse gas reduction. The McKinsey Quarterly: The Online Journal of McKinsey \& Co., 2008.

[25] European Commission, Externalities of energy. a research project, 2006. Available at: http: //www.externe.info/externe_2006.

[26] Genon, G. \& Brizio, E., Perspectives and limits for cement kilns as a destination for RDF. Waste Management, 28, pp. 2375-2385, 2008. doi: http://dx.doi.org/10.1016/j. wasman.2007.10.022

[27] Buonanno, G., et al., Dimensional and chemical characterization of particles at a downwind receptor site of a waste-to-energy plant. Waste Management, 30, pp. 1325-1333, 2010. doi: http://dx.doi.org/10.1016/j.wasman.2009.12.025

[28] Carreras-Sospedra, M., et al., Central power generation versus distributed generation - an air quality assessment in the South Coast Air Basin of California. Atmospheric Environment, 44, pp. 3215-3223, 2010. doi: http://dx.doi.org/10.1016/j.atmosenv.2010.05.017

[29] Panepinto, D. \& Genon, G., Environmental balance study for the construction of a biomass plant in a small town in Piedmont (Northern Italy). WIT Transactions on Ecology and the Environment, 143, pp. 279-290, 2011. doi: http://dx.doi.org/10.2495/ esus110241

[30] Lopez, J.L. \& Mandujano, C., Estimation of the impact in the air quality by the use of clean fuels (fuel oil versus natural gas). Catalysis Today, 106, pp. 176-179, 2005. doi: http://dx.doi.org/10.1016/j.cattod.2005.07.173

[31] Schleisner, L., Comparison of methodologies for externality assessment. Energy Policy, 28, pp. 1127-1136, 2000. doi: http://dx.doi.org/10.1016/s0301-4215(00)00084-7

[32] World Energy Council, Comparison of Energy Systems Using Life Cycle Assessment, World Energy Council, London, 2004. 